\title{
VERIFICAÇÃO DO DESEMPENHO DAS ESTACAS INJETADAS AUTOPERFURANTES EXECUTADAS EM SOLOS ARENOSOS PARA CONSTRUÇÃO DE USINA EÓLICA
}

\section{Verification of the performance of self-drilling injection piles executed in sandy soils for wind farm construction}

\author{
Rodrigo Rogério Cerqueira da Silva'
}

Recebido em 16 de fevereiro de 2017; recebido para revisão em 03 de junho de 2017;

aceito em 06 de julho de 2017; disponível on-line em 11 de agosto de 2017.

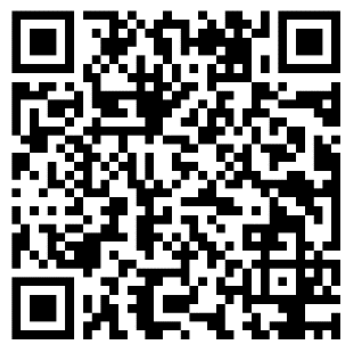

PALAVRAS CHAVE:

Estaca injetada autoperfurante; Prova de carga estática; Metodologia de execução; Métodos semi-empíricos; Solos arenosos.

\section{KEYWORDS:}

Self-drilling injection piles; Static load test; Execution methodology; Semi-empirical methods; Sandy soils.

\section{* Contato com o autor:}

${ }^{1}$ e-mail: rodrigorogeriomestrado@yahoo.com.br (R. R. C. Silva )

Doutorando Construções Rurais, Mestrado Construção Civil, Professor de Engenharia Civil da Universidade Nove de Julho. Parque de Usina Eólica localizado no Ceará, com a utilização das estacas injetadas autoperfurantes, executadas em presença de solos arenosos. No qual consiste em perfurar 0 solo com altíssima velocidade por rotação e "pull down", através da injeção simultânea de nata de cimento com medias pressões. Ocasionando na estaca um diâmetro final que pode obter o dobro do bit de perfuração, de acordo com o tipo de solo, gerado pelo efeito do jato da nata de cimento. Detalhando os processos executivos, verificando os aspectos técnicos e operacionais, para melhor compreender as características estruturais deste elemento. De forma a verificar "in situ" o desempenho deste novo tipo de fundação profunda, foram realizadas provas de carga, em estacas com diferentes diâmetros e comprimentos, realizadas em perfis estratigráficos de solos arenosos, para melhor avaliação de sua capacidade de carga. Analisando-se os ensaios das provas de carga interpretados a base da extrapolação da curva carga versus recalque e das previsões da capacidade de carga, obtidas por meio dos métodos semi-empíricos de correlação com ensaios de penetração (SPT), avaliando os padrões de execução desta tipologia de estaca injetada para comunidade geotécnica.

ABSTRACT: This paper aims to establish the selected solution to except the foundations of the Wind Energy Park in Ceará (Brazil), with an executive methodology of the self-drilling injection piles framed in loco in Sandy soil. In which the soil drilling is done with the highest speed by rotation and pull down, through the simultaneous injection of grouting with medium pressures. This kind of drilling causes in the pile a final diameter that can get the double bore bit, according to the type of soil, done by the grouting blast. The executive processes are detailed as a whole, and also presenting the pile materials composition, in order to understand the structural characteristics of this element. To verify the performance of this new kind of deep drilling, instrumentations were done: settlement control and load tests in constructions with different structural characteristics, in self-drilling injected piles with different diameters and length, done in stratigraphical sandy, for a better evaluation of its load capacity. Analyzing the essays of load tests interpreted in the basis of curve extrapolation load versus settlement and the previsions of the load capacity, obtained by semi-empirical methods correlating with the penetrations methods (SPT), offering information to the geotechnical community.

RESUMO: Apresenta-se neste trabalho a solução adotada para execução das fundações do 


\section{INTRODUÇÃO}

Desde que a humanidade começou a projetar e construir estruturas para diferentes usos e ambientes, sistemas de fundações tiveram de ser desenvolvidos para corresponder às necessidades arquitetônicas e estruturais. Em vez da utilização de fundações que exigem grandes quantidades de concreto em grandes áreas e grandes escavações em massa, fundações perfuradas ou estacas menores e mais profundas tornaram-se uma alternativa mais econômica, em que o aço embutido reforça o sistema de concreto, argamassa ou calda de cimento, que são seus principais componentes (SILVA, 2011).

Estacas injetadas autoperfurantes pertencem a esta categoria de elementos de fundação profunda, são muito simples, e estão se tornando cada vez mais populares na concepção da construção, este método associa barras ocas, às vezes em combinação com o seu interior barras sólidas, além de equipamentos mais simples, gerando uma execução simplificada de fácil controle e rapidez na instalação, apresentando dentre as estacas injetadas a menor relação custo/carga. Estacas injetadas autoperfurantes se diferenciam das demais podendo ser executadas com maiores inclinações entre zero e noventa graus. Seu processo de perfuração permite atingir grandes profundidades em terrenos com baixa resistência, 0 que lhes confere maior nível de carga transmitida ao solo por atrito lateral, comparando-se com outros tipos de estacas de mesmo diâmetro.

A criação desta estaca é produzir uma perfuração injetada, reforçando a microestaca e seguindo a ideia original da estaca raiz de Fernando Lizzi, surgida na década de 1950, em Nápoles (Itália) denominada de "Pali Radice". A contribuição desta técnica de fundação é introduzir para especialistas em engenharia de fundações, projetistas e empreiteiros, este novo sistema de perfuração denominado estaca injetada autoperfurante (EIA) com calda de cimento, podendo ser usado como sistema de reforço ou fundação de novas estruturas.

\section{OBJETIVO}

Como o uso da estaca injetada autoperfurante ainda não está disseminado, o objetivo da presente pesquisa é demonstrar o conceito desta técnica que poderá ser utilizada como reforço de fundação ou como estaca normal utilizável em qualquer condição como elemento estrutural. Demonstrando o seu desempenho em solos não coesivos através da construção de um parque eólica localizada no Estado do Ceará, considerada uma solução com vantagens técnicas e econômicas em relação às outras estacas injetadas, avaliando o comportamento das provas de carga estáticas por meio de métodos semi-empíricos de previsão de capacidade de carga disponíveis na literatura baseados em ensaios de NSPT, e através da extrapolação de curva carga $\mathrm{x}$ recalque para provas de carga interrompidas antes da ruptura de forma a caracterizar a capacidade de carga das estacas injetadas autoperfurantes.

\section{ESTACAS INJETADAS AUTOPERFURANTES}

As estacas injetadas autoperfurantes são estacas de pequeno diâmetro moldada in loco, a qual consiste em perfurar o solo com altíssima velocidade por rotação e pull down com injeção simultânea. Realizada por um tubo de aço sem costura (31/2" de diâmetro) com alta resistência de comprimento com cerca de $50 \mathrm{~cm}$ superior à profundidade do furo com ponta cortante, esta que é a própria armação principal da estaca (Figura 1). A injeção de nata de cimento é realizada por dentro do tubo vazado (sentido descendente) com refluxo (sentido ascendente) entre a seção anelar formada pelo perímetro externo do tubo e a parede de contato do solo. 


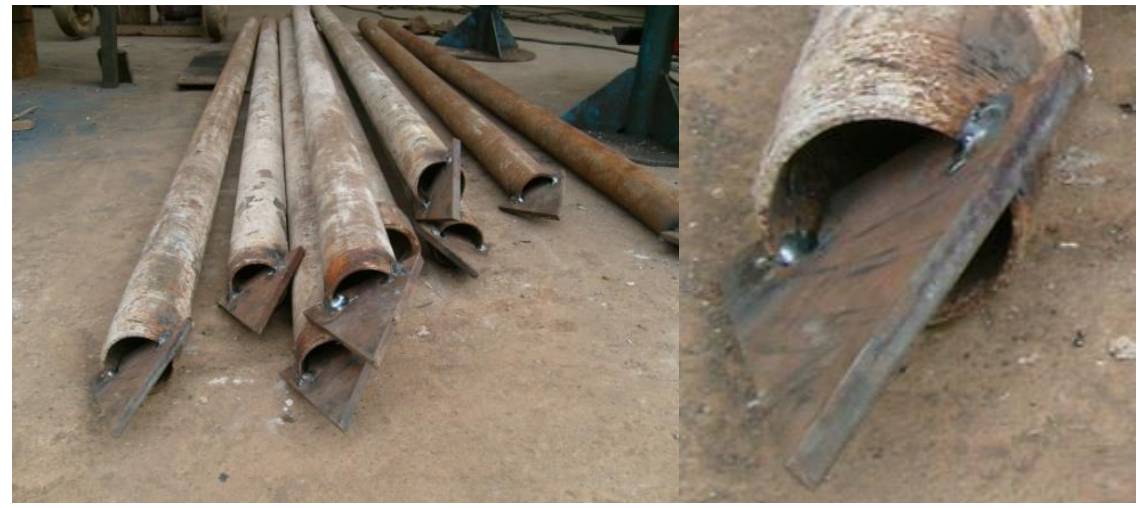

FIGURA 1: Detalhe da ponteira cortante com passagem para calda de cimento.

FONTE: Autoria Própria.

Segundo Aschenbroich (2001) as pressões médias da ordem de $\left(5\right.$ a $\left.10 \mathrm{Kg} / \mathrm{cm}^{2}\right)$ contribuem no avanço da perfuração melhorando o solo adjacente, aumentando seu diâmetro através do efeito gerado pelo jato da nata de cimento. A parte excedente ao furo serve de suporte para auxiliar as operações de injeção e blocos de coroamento, pode-se concluir que este sistema de fundação autoperfurante reúne a técnica da microestaca tubular injetada com alguma similaridade da técnica do Jet Grouting.

Estudos realizados por Pachla (2016), Samokhvalov et al. (2016), Grabe e Pucker (2015), verificaram que o alargamento do fuste ocasionado pelo aumento das pressões em estacas injetadas, provocam alterações das características físicas e mecânicas na área do maciço do solo próximo da estacas devido a compactação radial do solo, aumentando a densidade em torno de $25 \%$, módulo de deformação em $64 \%$ e diminuindo em cerca de $38 \%$ o teor de umidade, os pesquisadores verificaram que a mudança desses parâmetros do solo contribuíram para aumentar a capacidade de carga das estacas em $20 \%$ em relação a verificação de estacas injetadas sem pressão.

Esta técnica é executada sem vibração e abaixo dos limites de ruído nas obras a qual exige somente pequenas perfurações, com menor número de equipamentos de tamanho reduzido e capacidade instalada, ocasionando menor prejuízo ao meio ambiente.

As manobras são perdidas evitando-se o trabalho de retirar tubos de encamisamento e colocação das barras de armadura, como nos sistemas convencionais. Realizar o furo cimentado com a própria armação confere a este tipo de estaca a característica de provocar mínima perturbação do maciço, duplicando em geral a produtividade frente a trabalhos com tubos encamisados. Esta característica representa um atrativo adicional especialmente no caso de interferências urbanas complexas, além da rapidez de execução dobrando em geral a produtividade, exigindo uma equipe mínima formada por: encarregado geral de serviços, operador de perfuratriz, injetador e auxiliares (prático e geral).

Silva (2015) comparou estacas raiz, microestaca tubular e estaca injetada autoperfurantes através da capacidade carga e produtividade destas estacas executadas em solo residual de gnaisse. $O$ pesquisador verificou através de provas de carga estática a tração, que as estacas injetadas autoperfurantes obtiveram capacidade de carga superior em $25 \%$ em relação as outras estacas injetadas, além de uma produtividade de três vezes mais que as estacas tipo raiz e seis vezes mais em relação a microestaca tubular injetada.

A autoperfuração com nata de alta resistência gera um diâmetro de no máximo o dobro do bit de perfuração, além do aumento da capacidade de carga da estaca tubular. O corpo formado por calda de cimento garante uma interação radial da barra de ancoragem no solo e também fornece grande proteção anticorrosiva (Figura 2). 


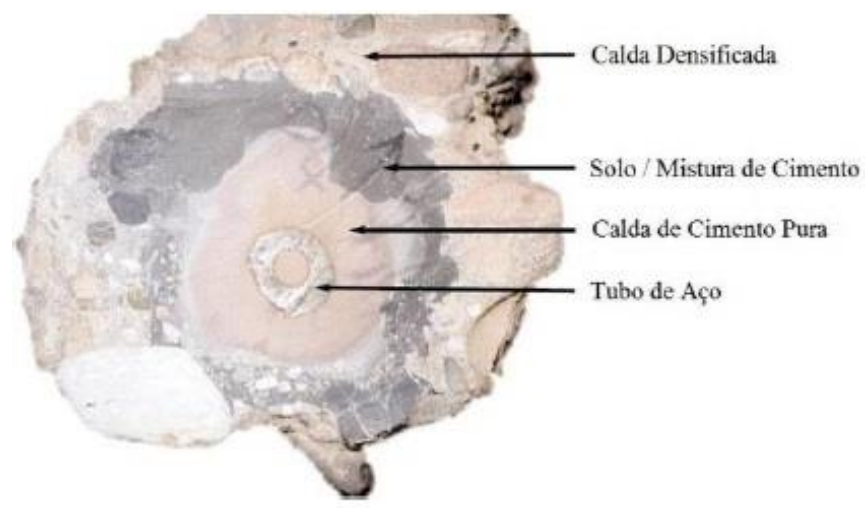

FIGURA 2: Seção típica de uma estaca injetada autoperfurante exumada. FONTE: Silva (2011).

De acordo com Costa Nunes (1985), o problema da corrosão das armações das estacas injetadas é semelhante ao da corrosão de ancoragens injetadas. Do mesmo modo que as ancoragens, as estacas injetadas devem apresentar uma segunda linha de defesa das fundações contra a corrosão, além do envolvimento da armação com calda de cimento. Costa Nunes (1985), ressalta que o fato da maioria das estacas injetadas trabalharem a compressão, diminui a deterioração da proteção fornecida pelo envelhecimento com calda ou argamassa. De acordo com os ensaios realizados pela Ischebeck (1999), em geral o diâmetro final do corpo injetado é muito diferente do diâmetro nominal da perfuração do furo (Figura 3). Para os diferentes tipos de solo, obtém-se o diâmetro (D) em: 2,0 x diâmetro do bit de perfuração, em solos com presença de cascalhos de tamanho grande a médio, 1,5 $\mathrm{x}$ diâmetro do bit de perfuração, em solos arenosos com ou sem presença de cascalhos $e$ 1,4 x diâmetro do bit de perfuração, em solos argilosos e siltosos.

A injeção do fluido cimentante funciona como: (1) elemento de refrigeração da ferramenta de corte, (2) retirada de resíduo e (3) estabilizante da perfuração, da mesma maneira que as lamas tixotrópicas empregadas na perfuração de estacas ou de chumbadores. Para tanto, é necessária a utilização de equipamento de alto torque da ordem de 1000 kgf.m e pull down com cerca de 5000 kgf. Caso estes dados não sejam observados em campo, haverá sempre a possibilidade de ocorrer o aprisionamento da composição das hastes, em função da liberação de calor produzido durante a perfuração ocasionando a aceleração da pega da nata antes de atingir a cota de projeto. De acordo com Silva (2011) a perfuração com calda de cimento fator $A / C(0,7)$ aplicando uma pressão média (5 á 10 $\mathrm{Kg} / \mathrm{cm}^{2}$ ) produz uma junta de infiltração na área entre o cimento e o solo, devido a um comportamento elástico linear de tensãodeformação. Para garantir melhor ancoragem e formação de um bulbo de maior diâmetro, nos últimos três metros, a injeção da calda de cimento deve ser mais demorada mudando também o seu fator A/C. Este procedimento promove melhoria nos resultados no final da perfuração, mantendo a rotação sem o avanço, com uma calda rica de cimento $A / C(0,5)$. A pressão deverá ser aumentada em função dos terrenos para atender um bulbo contínuo e ininterrupto, que efetivamente expulsa todos os detritos desde o fundo da perfuração.

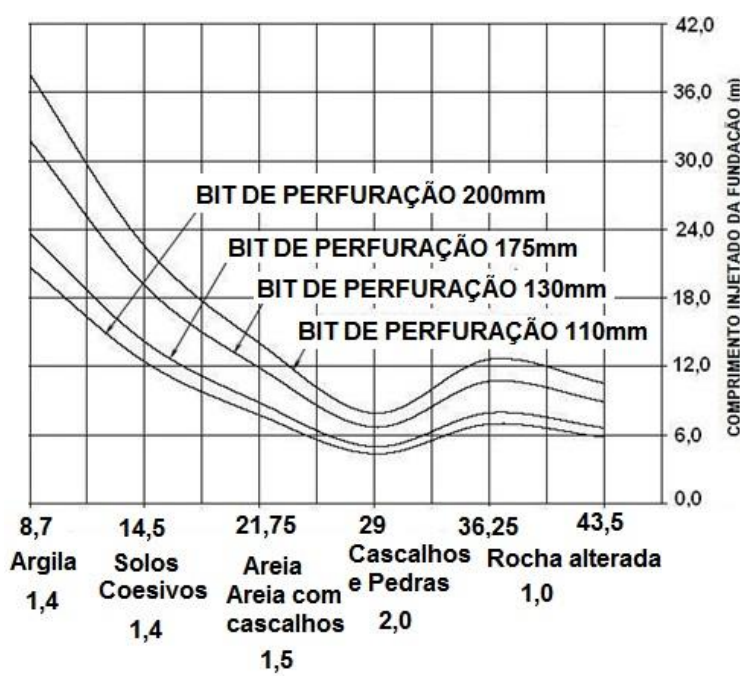

FIGURA 3: Fator de multiplicação em relação ao bit de perfuração e tipo de solo.

FONTE: Silva (2011).

O aumento da capacidade de carga 
através da injeção na base das estacas foi analisado por Aubram et al. (2015) e Moraes (2010), através de tubos com válvulas manchetes colocadas na base das armaduras, após a concretagem o volume de calda injetado aumentou a capacidade de carga em $49 \%$ em relação as estacas sem injeção, devido a melhoria do contato entre solo e ponta da estaca provocado pela alta pressão de injeção de calda, garantindo uma maior parcela da resistência de ponta.

Segundo Silva (2011) esta melhoria é explicada pelo início do rápido endurecimento do cimento, formando um solo que se desprende e encaixa na saída de injeção, formando um obturador natural aumentando a pressão. A este procedimento denominamos (injeção dinâmica) em oposição à (injeção estática) das microestaca tradicionais, que utilizam válvulas manchetes para aumentar a pressão de injeção e ocasionar o rompimento do solo introduzindo nestas fraturas natas de cimento.

A realização da injeção é uma parte do trabalho que está relacionada ao tipo de solo refletindo especialmente no consumo de cimento, sendo a quantidade estimada de cimento absorvido em dois sacos por metro linear de estaca, este sistema de execução permite obter uma "ancoragem de bulbo contínuo" super armada em operação única, com armadura tubular de alta resistência.

\section{METODOLOGIA}

Como objeto de estudo, foi analisado o comportamento das estacas injetadas autoperfurantes, através de provas de cargas estática na construção de um grande Parque Eólico na Região Nordeste do Brasil, na cidade de AracatiCE.

\subsection{CARACTERIZAÇÃO DA ÁREA DE ESTUDO}

Geralmente a construção de um Parque Eólico tende a se concentrar em atividades de montagem mais mecanizada dos aerogeradores do que na execução em obras de infraestrutura civil, para a instalação das torres faz-se necessário a execução de bases de apoio que receberão e transmitirão cargas provenientes dos aerogeradores para as fundações. Estes tipos de estrutura recebem cargas verticais e horizontais, além de momentos fletores na sua base, garantindo papel importante em seu funcionamento eletromecânico.

De acordo Pessanha et al. (2009) a análise estatística das medições anemométricas fornece uma estimativa mais precisa do potencial eólico, permitindo assim uma melhor avaliação da viabilidade econômica, além de fornecer informações fundamentais para a seleção da turbina eólica mais adequada ao comportamento do vento no local onde se pretende construir o aproveitamento eólico.

A decisão da implantação do empreendimento eólico no Sudeste do Ceará foram baseadas em parâmetros encontrados através da análise estatística dos registros anemométricos, demonstrando a viabilidade da instalação do parque eólico entre a foz do rio Jaguaribe e a praia de Canoa Quebrada, dividido em dois parques denominados Bons Ventos e Canoa Quebrada composto por 67 aerogeradores, cada aerogerador possui capacidade de 2,1 megawatts o que corresponderá a uma geração de 138,5 megawatts, suficientes para abastecer uma cidade de 500 mil habitantes.

O subsolo local do Parque de Usina Eólica pertence ao plano costeiro do estado do Ceará, representado por depósitos sedimentares da costa brasileira ocasionados pelas flutuações do nível do mar. A área de estudo (Figura 4) apresenta um perfil típico da região de implantação da obra, formada basicamente por depósitos litorâneos cenozóicos, ao qual constituem grandes depósitos eólicos formados a partir da remoção da face de praia pela deflação eólica originando as paleodunas e dunas. As paleodunas de acordo Fonteles (2003), ocorrem em uma faixa mais ou menos contínua ao longo da costa cearense, repousando sobre os sedimentos da Formação Barreiras, compostos por sedimentos areno-argilosos, consolidados a inconsolidados, com coloração avermelhada, creme ou amarelada, mal selecionados, de granulação variando de fina a média, com níveis conglomeráticos e lateríticos, em 
grande parte coberta pelas dunas móveis ou recentes. São compostas por areias bem selecionadas de granulometria fina a média, por vezes siltosa com tons amarelados, alaranjados e acinzentados, de composição quartzosa e/ou quartzo-feldspática.

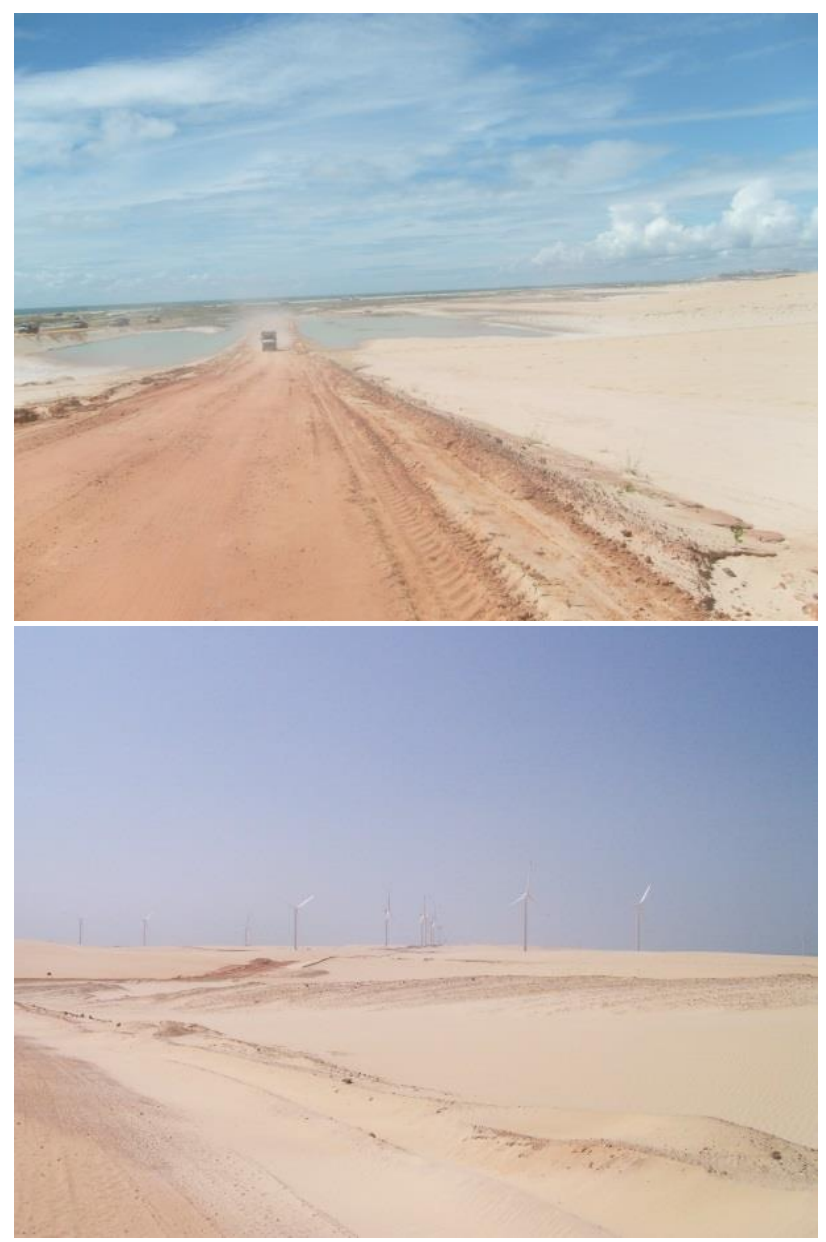

FIGURA 4: Perfil geológico local, da construção das torres de usinas eólicas.

FONTE: Autoria Própria.

As dunas distribuem-se como um cordão contínuo disposto paralelamente a linha da costa, com uma largura média de 2 a 3 quilômetros e espessuras atingindo 30 metros, compostas por areias de cor branca, bem selecionadas de granulometria fina a média, quartzosas, com grão foscos e arredondados (Fonteles, 2003). De acordo com o mapeamento geológico realizado por Marino et. al (2012) o litoral do Ceará, os sedimentos praiais são constituídos predominantemente por areia média, apresentando grãos de quartzo subarredondados e de esferecidade média, com caracterisiticas granulométricas variando de areia grossa a fina em função do estágio evolutivo da costa, consequência de modificações espaciais e temporais.

Dessa forma em linhas gerais, o perfil geotécnico na área de implantação do Parque Eólico é caracterizado por mais de 30 metros de solos arenosos, com compacidade crescente com a profundidade os quais fazem parte destes sistemas geológicos.

\subsection{CRITÉRIOS DE ESCOLHA DAS ESTACAS INJETADAS AUTOPERFURANTES}

O projeto inicial previa fundações profundas do tipo hélice contínua monitorada, sendo inviável para o local da obra formado por dunas. Levando ao adiamento da construção do Parque Eólico devido a metodologia de execução deste tipo de estaca, conforme o exposto a seguir: a perfuratriz não tem estabilidade devido às condições do solo de apoio das esteiras (solo arenoso); aumento do número de maquinário como guindaste auxiliar para introduzir a armação; dependência de usina de concreto com distâncias em mais de 3 horas até o local da obra; comprometimento da resistência devido o vencimento durante a concretagem com risco de iniciar repentinamente a pega levando a substituir o traço e usar aditivos retardadores; entupimento da tubulação de injeção devido à pega ou segregação dos materiais do concreto.

Os aspectos acima citados além de outros, fez com que as estacas injetadas autoperfurantes fossem a solução pelo fato de não apresentarem os inconvenientes das estacas hélice contínua, tendo como principal vantagem a central de injeção in loco. As torres foram apoiadas em bases circulares de concreto com 11 metros de diâmetro, sendo que estes elementos possuem fundações profundas constituídas de estacas injetadas autoperfurantes (Figura 5-a), foram projetadas para cada base 36 estacas com inclinação de 0 a 12 graus em relação a vertical com diâmetro 300 mm (Figura 5-b), com um total de 2.412 estacas com uma metragem de estacas variando entre 10 a 27 metros.

A verificação do desempenho de estacas verticais $e$ inclinadas foram analisadas por 
Carbonari et al. (2017), avaliando os efeitos da interação solo-estrutura, através da criação de modelos numéricos avaliando a resistência das estacas por cada camada de solo, através da ação sísmica de pontes. Os pesquisadores verificaram através de modelos que as estacas inclinadas suportam mais as rupturas de cisalhamento e momentos de flexão quando comparadas as estacas verticais, relatando que o movimento sísmico transmitido de superestruturas aplicado ao solo depende da inclinação das estacas.

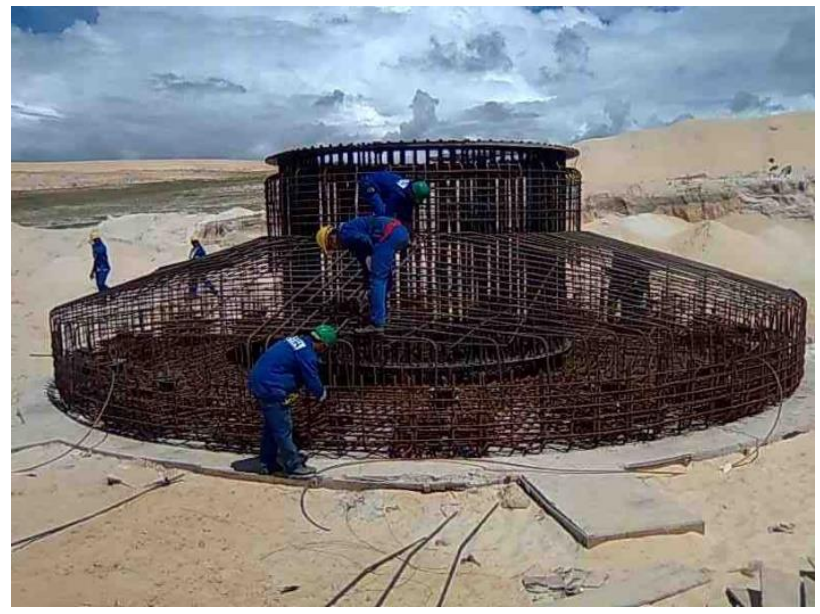

[a]

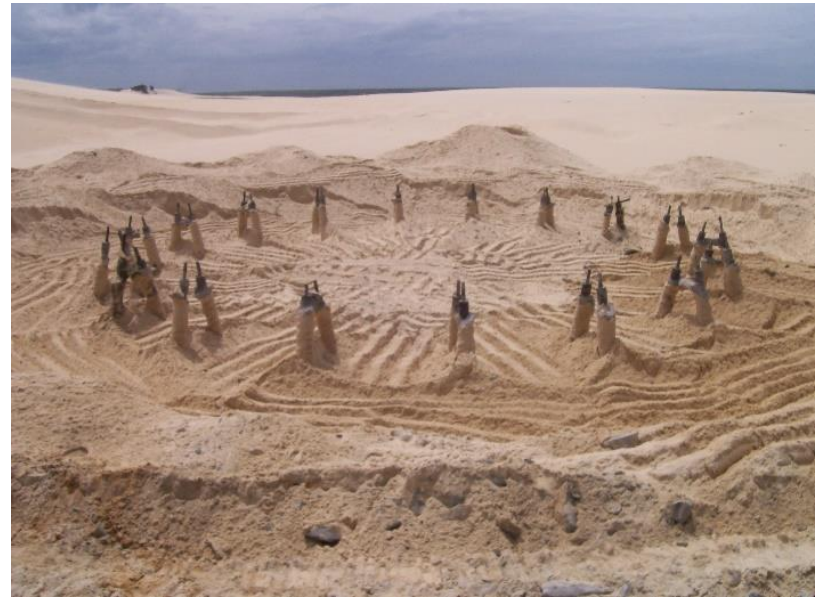

[b]

FIGURA 5: Vista geral das bases, [a] seção da base com estacas injetadas autoperfurantes, [b] localização das estacas.

FONTE: Autoria Própria.

\subsection{ENSAIOS DE CAMPOS REALIZADOS}

Para analisar o comportamento da curva $x$ carga recalque dos elementos de fundação foram realizadas cinco provas de carga estáticas com carregamento lento no Parque Eólico Bons Ventos. Os trabalhos envolveram uma prova de carga a compressão, duas a tração e uma com carregamentos tipo horizontal localizado na base denominada (NCQ -28). No mesmo Parque em outra base (NCQ-23) foram realizados os mesmos ensaios a fim de determinar a carga de ruptura das estacas. Para os ensaios de compressão e tração foram efetuados carregamentos com uma carga além da carga de projeto das estacas. Estes ensaios foram executados sobre cavaletes compostos por estacas injetadas autoperfurante com 18,70 m de comprimento. No Parque Eólico de Canoa Quebrada, encontra-se a base para aerogeradores (NCQ-11). Nesta base foram realizadas três provas de carga estáticas, um ensaio a compressão para estaca com $12,45 \mathrm{~m}$, e dois a tração em estacas de $12,00 \mathrm{~m}$. A aplicação de carga no cavalete foi feita por intermédio de um conjunto de bomba manual e macaco hidráulico com capacidade para 400 toneladas, com um sistema de atirantamento utilizando-se as estacas injetadas autoperfurantes. O sistema completo reagiu em 3 cavaletes de compressão, 6 cavaletes de tração e 2 cavaletes com carregamento horizontal, sendo que na estaca de compressão foi adicionada no seu topo uma placa metálica de $20 \mathrm{~mm}$ para receber o macaco hidráulico (Figura 6a). O carregamento horizontal aplicado sobre o macaco hidráulico foi realizado com o auxílio de um trator no sentido de maior inércia do cavalete (Figura 6b), a transferência de carga do macaco hidráulico para os elementos de compressão e tração foram realizados através de uma viga metálica dupla com 4,00 m de comprimento.

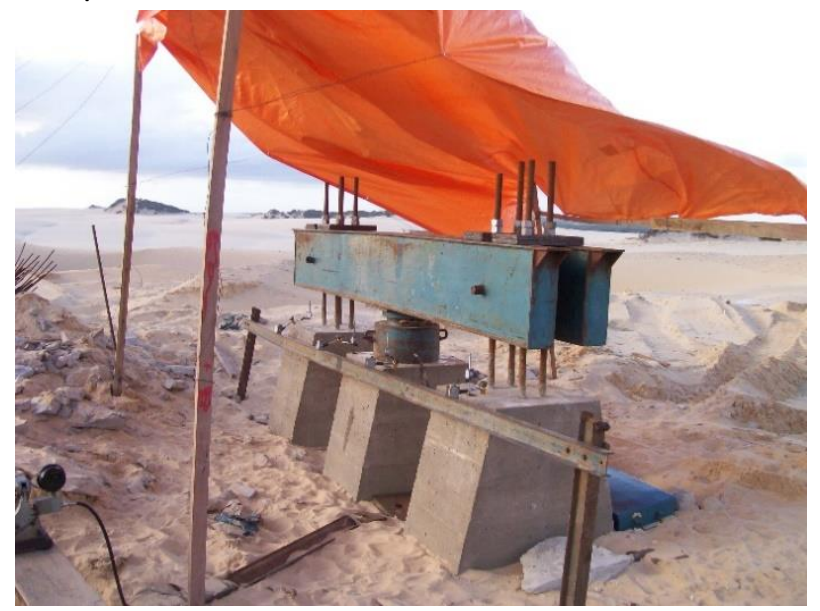

[a]

FIGURA 6: Área da pesquisa, [a] sistema de reação para ensaio de compressão, [b] Prova de carga horizontal (CONTINUA...).

FONTE: Autoria Própria. 


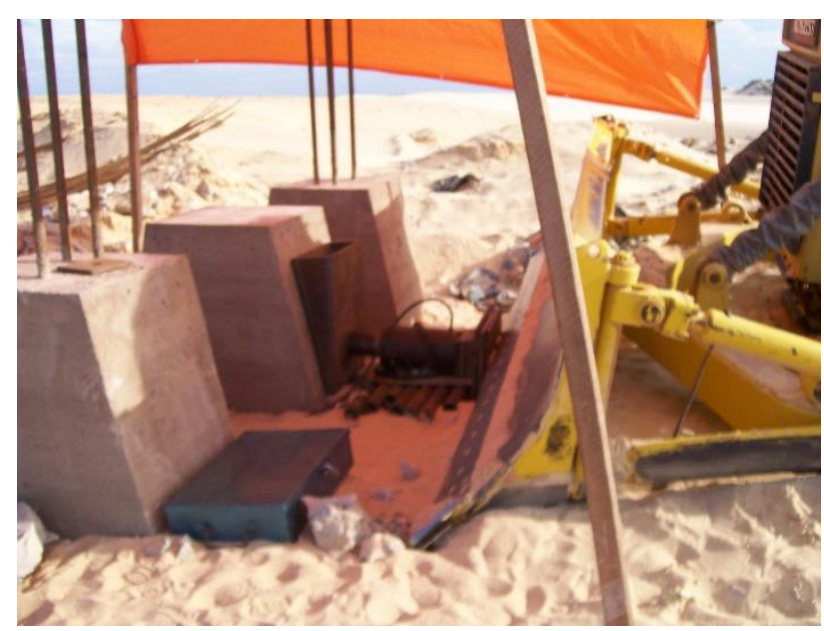

[b]

FIGURA 6: Área da pesquisa, [a] sistema de reação para ensaio de compressão, [b] Prova de carga horizontal. (CONTINUAÇÃO).

FONTE: Autoria Própria.

\subsection{ANÁLISE DO DESEMPENHO DAS ESTACAS INJETADAS AUTOPERFURMANTES}

Os resultados das previsões de carga de ruptura, foram calculados a partir de um valor de NSPT, foram realizados a partir do diâmetro nominal ocasionado pelo jato da nata de cimento e das sondagens mais próximas da estaca ensaiada. Respeitando os limites fixados na revisão bibliográfica para cada método, aplicando-se a previsão de carga das estacas nesta pesquisa através de: Aoki \& Velloso (1975), Decourt \& Quaresma (1978/1982), David Cabral (1986) e Ivan Joppert Jr. (2004). Sendo que os valores para os parâmetros $\alpha$ e $\beta$ para o Método Decourt \& Quaresma serão os mesmos recomendados para o comportamento da estaca tipo raiz, e os valores dos coeficientes de segurança F1 e F2 do Método de Aoki \& Velloso são os recomendados para estacas escavadas em geral. Considerando que a avaliação do desempenho da capacidade de carga das estacas foi realizada conforme as características das provas de carga em que a obra foi submetida (compressão e tração).

A capacidade de carga das estacas à tração será realizada por meio dos métodos semiempíricos, próprios para os esforços de compressão, considerando-se somente a parcela de resistência lateral desprezando-se a parcela referente à resistência de ponta. Segundo Lamare
Neto (1985) as dificuldades normalmente encontradas para determinação analítica da capacidade de carga de estacas são ampliadas em estacas injetadas face ao seu processo executivo, que resulta em geometria não bem definida e maiores dificuldades na quantificação das tensões radiais existentes ao longo do seu fuste.

\section{PROVAS DE CARGA ESTÁTICA}

Os ensaios de todas as estacas foram realizados junto as suas respectivas bases para demonstrar o melhor comportamento junto às características geológicas e geotécnicas do solo local. A Figura 7 apresenta a curva carga $x$ recalque para a estaca EC-01 (18,70 m) localizada junto a Base NCQ-28. Nesta estaca foi realizado um ensaio de compressão com carga máxima aplicada de 320 $t$, os recalques medidos nos quatro extensômetros apresentaram valores uniformes, comprovando que a carga foi aplicada sem excentricidade. Para a carga máxima aplicada no ensaio, a estaca apresentou recalque médio máximo equivalente a $3 \%$ do seu diâmetro ( $9 \mathrm{~mm})$, após seu descarregamento a sua deformação residual foi ( $2 \mathrm{~mm}$ ), ou seja $0,6 \%$ do diâmetro da estaca. $O$ gráfico da figura 7 é composto de segmentos retilíneos não caracterizando uma curva de ruptura bem definida, típico das estacas injetadas.

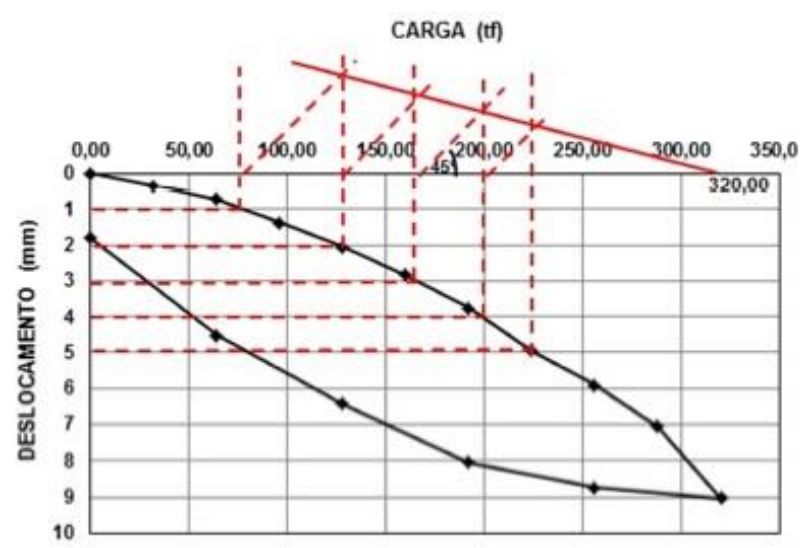

FIGURA 7: Curva carga $x$ recalque da estaca EC-01 Base NCQ 28.

FONTE: Autoria Própria.

Na mesma base NCQ-28 foram ensaiadas duas estacas submetidas à tração. A estaca ET-01 
submetida ao primeiro ensaio com uma carga de 160 tf, obteve leituras dos extensômetros uniformes, demonstrando que as excentricidades verificadas foram insignificantes, com deslocamento máximo de $4 \%$ do diâmetro da estaca (Figura 8-a). Da mesma forma que a estaca anterior, a estaca ET-02 ensaiada a tração foi submetida a uma carga de $160 \mathrm{tf}$, apresentando os recalques medidos nos quatro extensômetros valores uniformes (Figura 8-b). As estacas apresentaram comportamento retilíneo, tanto na fase elástica como na fase plástica da curva, dificultando a interpretação de ruptura pelo predomínio do comportamento elástico.

Foram realizadas duas provas de cargas do tipo lenta com aplicação de esforços transversais nas EIA. Na Base NCQ-28 a carga máxima transversal aplicada no ensaio foi de $30 \mathrm{t}$, sendo que a carga de trabalho determinada era de 7,5 t, demonstrando que a estaca sofreu pequenos deslocamentos horizontais (Figura 9a). Junto a Base NCQ-23 a estaca teste submetida a carregamento horizontal, apresentou comportamento da curva carga $\mathrm{x}$ recalque com características similares a curva da base NCQ-28. Não apresentado ruptura bem definida conservando a mesma tendência de evolução para uma carga de ensaio de $30 \mathrm{tf}$ com deslocamentos junto ao topo da estaca de $5 \mathrm{~mm}$ (Figura 9b).

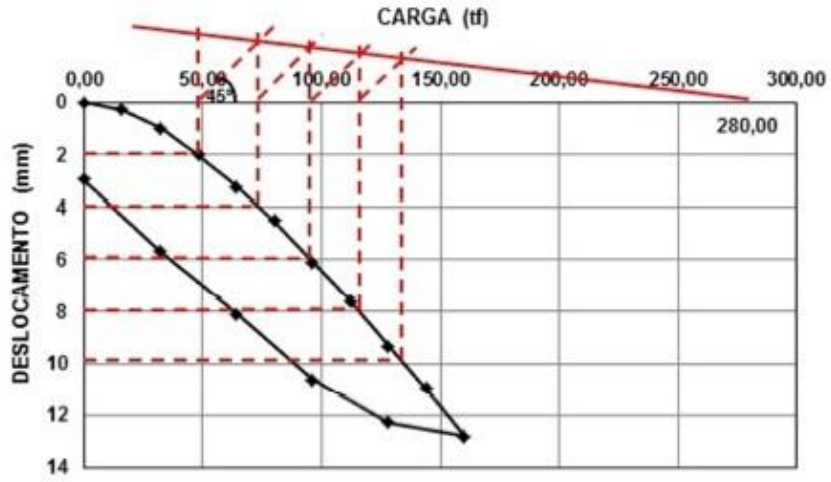

[a]

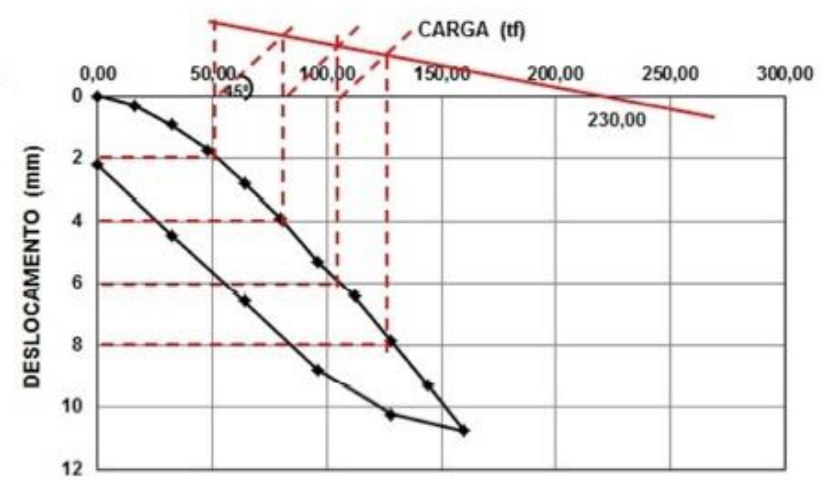

[b]

FIGURA 8: [a] Curva carga x recalque estaca ET-01, [b] Curva carga x recalque estaca ET-02 Base NCQ-28. FONTE: Autoria Própria.

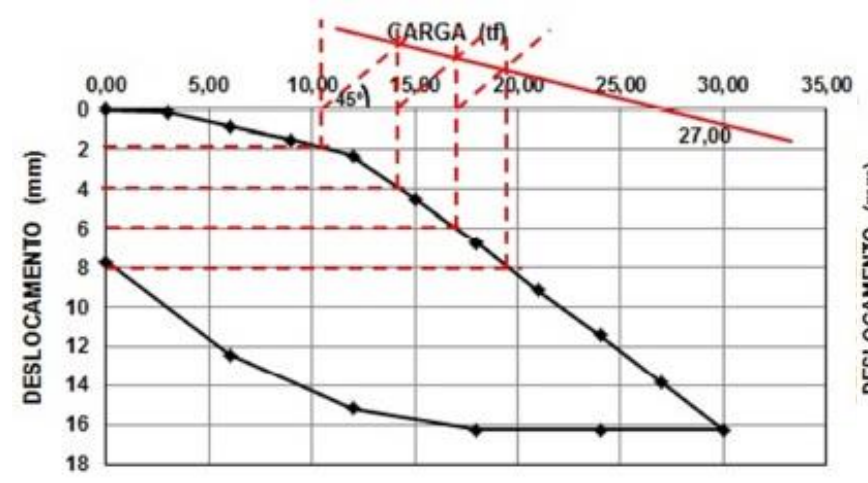

[a]

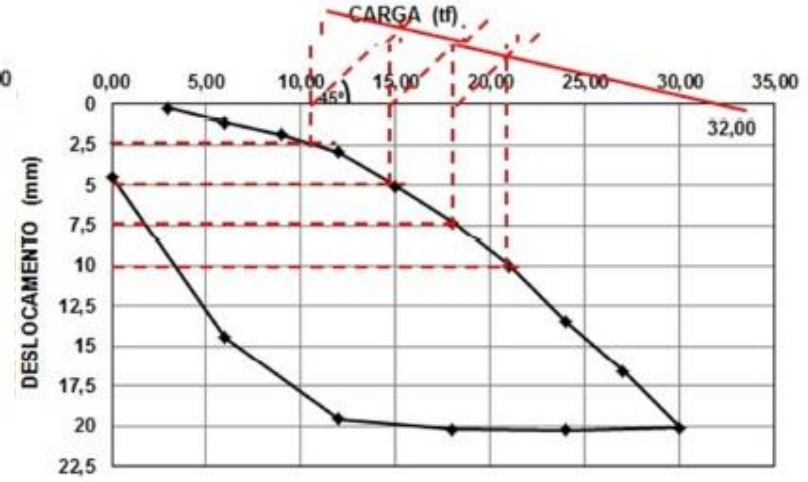

[b]

FIGURA 9: [a] Curva carga x recalque estaca EH-01 Base NCQ-28, [b] Curva carga x recalque estaca EH-01 Base NCQ23.

FONTE: Autoria Própria. 
A fim de determinar a carga de ruptura das estacas e contribuir com a conclusão da prova de carga foi efetuado um carregamento muito além da carga de projeto das estacas teste da Base NCQ-23. Assim iniciou-se a implementação de cargas com estágio de 50 toneladas, para cada estágio a leitura foi feita imediatamente após ser atingida a carga programada, em seguida iniciado o novo carregamento. Este plano de reação de carga não está fundamento na NBR 12131 (ABNT, 1992), sendo a carga máxima atingida de 241 toneladas para a estaca de compressão e de 120 toneladas para cada uma das estacas á tração. 0 carregamento foi interrompido devido a um vazamento do macaco hidráulico, complementado a determinação da sua ruptura através da extrapolação pelo método de Mazurkiewicz (1972). O descarregamento foi feito de uma só vez e as leituras finais foram feitas após o descarregamento total do sistema, nos gráficos abaixo podemos ver os deslocamentos medidos para cada uma destas estacas.

Apresenta-se na Figura 10 a curva característica da estaca EC01 ensaiada até a ruptura.

Pode-se observar um comportamento de ruptura abrupto, no qual o elemento de fundação suporta os incrementos de carga até valores próximos a carga de ruptura, na maior parte absorvida de pequenas deformações elásticas, tanto do solo quanto do material da estaca (aço e calda). Este tipo de comportamento pode ser influenciado pela presença do solo arenoso, que encontra-se envolto a estaca aumentando o seu atrito lateral. Para as estacas ET-01 ensaiada até a iminência de ruptura, o ensaio apresentou um gráfico linear após um carregamento de 25 tf. 0 primeiro segmento retilíneo da curva carga $x$ recalque é ocasionado por pequenos deslocamentos, onde a carga é transferida para o solo através do fuste da estaca (Figura 11-a). Analisando a (Figura 11-b) é possível verificar que a curva recalque, no segundo ensaio até a ruptura para a estaca ET-02, seguiu a mesma tendência verificada para a estaca ET-01, sem que houvesse a ocorrência de decréscimo de carga.

Para as estacas ensaiadas até a ruptura, as cargas aplicadas conseguiram definir o comportamento das curvas carga $\mathrm{x}$ recalque através das duas fases, elástica e plástica, sendo que a fase de ruptura não foi bem definida devido a problemas em função do macaco hidráulico. Na base NCQ-11 as estacas também foram submetidas a ensaios de compressão e tração. Para a estaca EC-01 submetida à compressão a (Figura 12) apresenta a curva carga $\mathrm{x}$ recalque com carregamento previsto a 2 vezes a carga de trabalho, apresentando um gráfico praticamente linear, dificultando a extrapolação da curva para obter a carga de ruptura. Mesmo aumentando o carregamento na fase plástica a curva se torna contínua e ininterrupta até a carga aplicada de $150 \mathrm{tf}$, com recalque máximo de $2 \%$ em relação ao diâmetro da estaca.

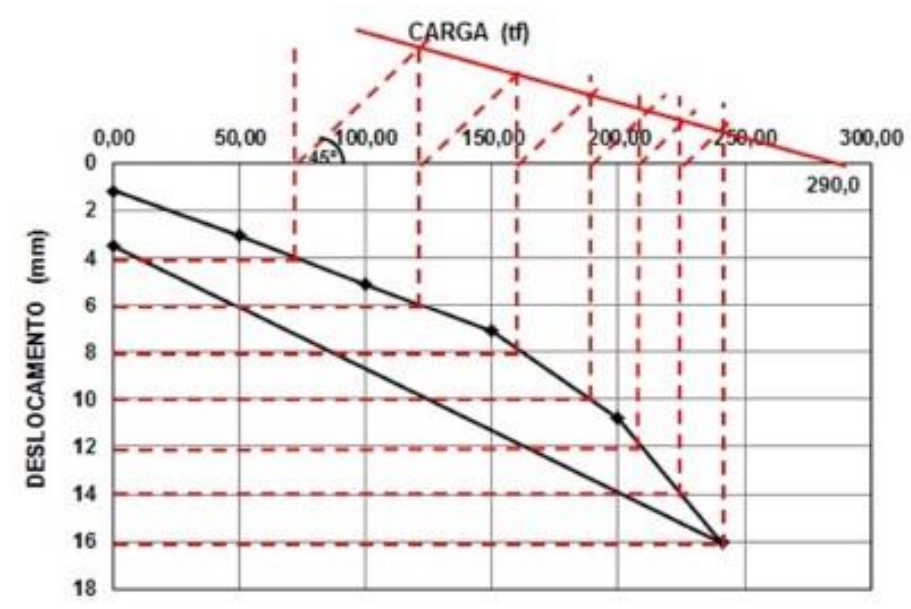

FIGURA 10: Curva carga $x$ recalque até a ruptura estaca EC-01 base NCQ-23.

FONTE: Autoria Própria. 


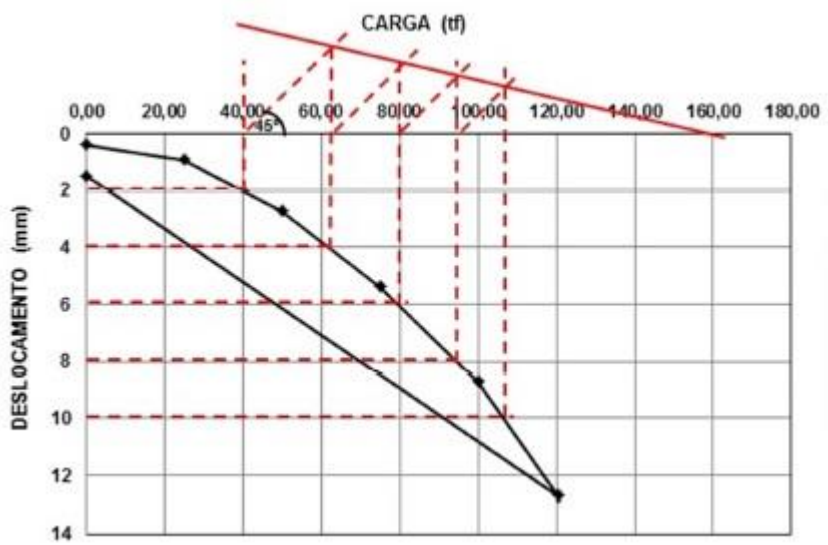

[a]

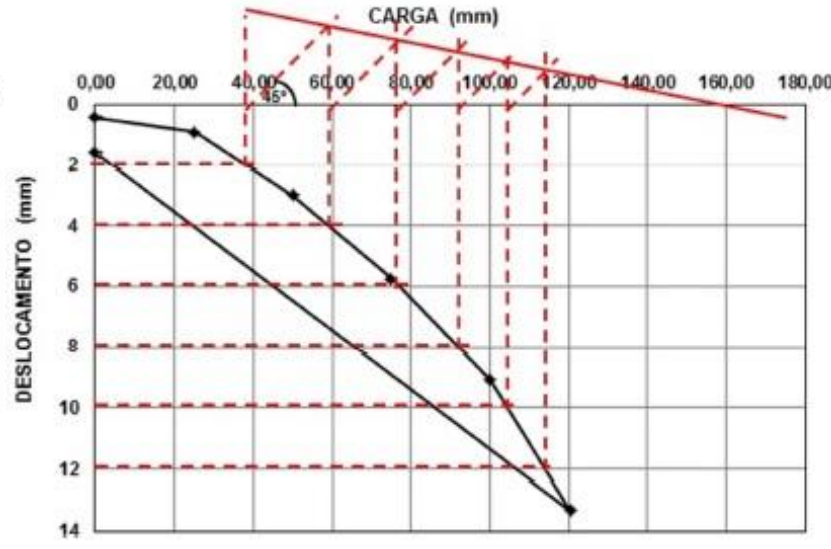

[b]

FIGURA 11: [a] Curva carga $\mathrm{x}$ recalque até a ruptura ET-01, [b] Curva carga $\mathrm{x}$ recalque até a ruptura ET-02 base NCQ-23. FONTE: Autoria Própria.

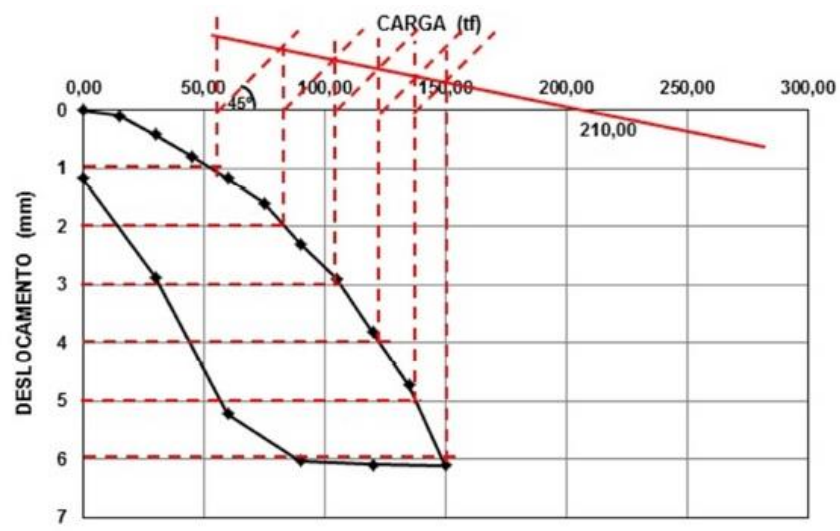

FIGURA 12: Curva carga x recalque da estaca EC-01 Base NCQ-11. FONTE: Autoria Própria.

$\mathrm{Na}$ (Figura 13-a e 13-b), apresenta-se as curvas referentes aos ensaios de tração nas estacas ET-01 e ET-02, conforme a NBR 6122/2010, com carga correspondente a 2 vezes a carga de trabalho, ou seja, $75 \mathrm{tf}$, indicando após a estabilização da carga a plena atividade da interação solo-elemento estrutural.

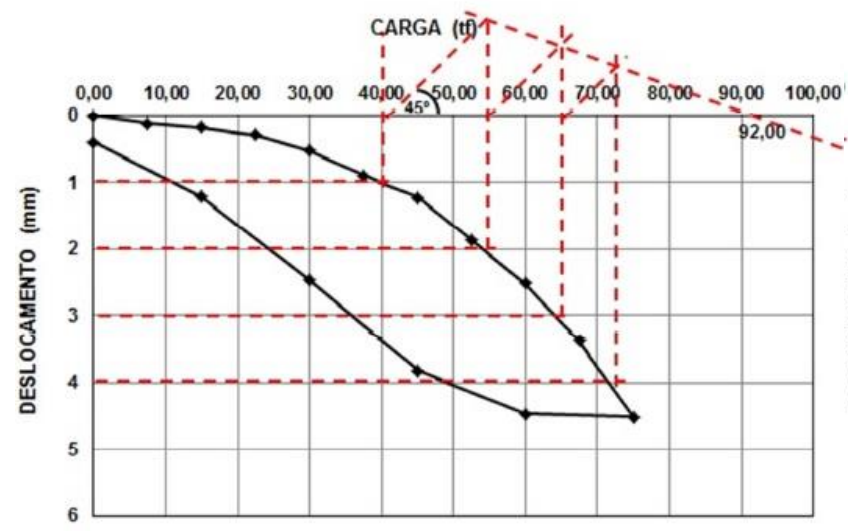

[a]
As estacas apresentaram mesmo comportamento no gráfico na fase plástica, o carregamento da carga provocou um aumento progressivo dos recalques, porém não apresentaram uma ruptura bem definida. 0 recalque médio para os dois ensaios foi equivalente a $5 \mathrm{~mm}$ aproximadamente $2 \%$ do diâmetro.

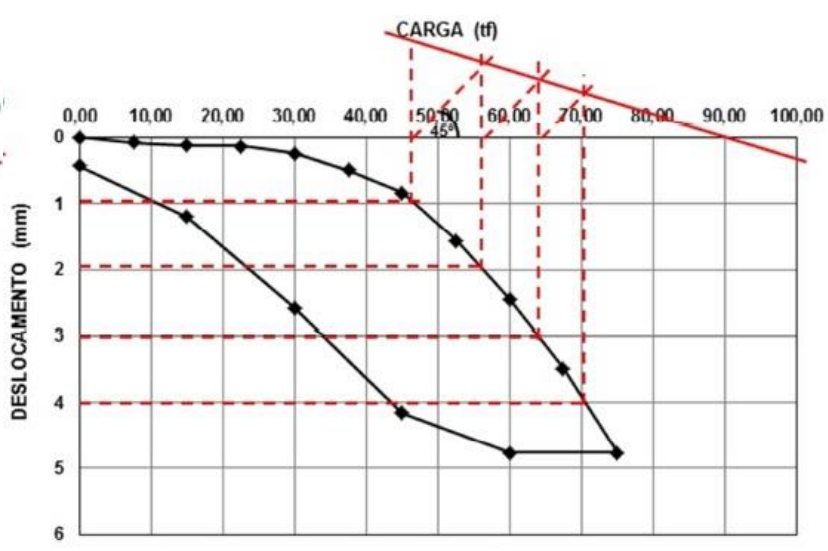

[b]

FIGURA 13: [a] curva carga $x$ recalque da estaca ET-01, [b] curva carga $x$ recalque da estaca ET-02 Base NCQ-11. FONTE: Autoria Própria. 


\section{RESULTADOS E DISCUSSÕES}

\subsection{ANÁLISE DOS RESULTADOS A PARTIR DA CURVA CARGA X RECALQUE}

Através da curva carga $\mathrm{x}$ recalque das provas de cargas, foi utilizado o método para extrapolação das cargas por Mazurkiewicz (1972) para determinar a carga de ruptura, utilizando esses resultados para confrontar com os valores determinados pelos métodos semi-empíricos. A Tabela 1 apresenta um resumo dos resultados das provas de carga, comparando com os resultados de extrapolação da curva que busca através do método uma assíntota vertical.

Todas as estacas ensaiadas à compressão ou à tração apresentaram desempenho satisfatório conforme o indicado a norma NBR 6122 (ABNT, 2010) devendo o fator de segurança ser no mínimo ou igual a 2,0 em relação à carga de ruptura obtida na prova de carga ou por sua extrapolação.

\subsection{ANÁLISE DOS RESULTADOS A PARTIR DOS}

\section{VALORES $\mathbf{N}_{S P T}$}

Para fins de ordem prática ao referir-se nas tabelas aos métodos utilizados, optou-se por siglas como: A \& V, D \& Q, D. C. e I. J. J., para os métodos de Aoki \& Velloso, Decourt \& Quaresma, Davi Cabral e Ivan Joppert Jr. As Tabelas 2 e 3 apresentam os valores previstos pelos métodos semi-empíricos junto com os resultados de Mazurkiewicz (1972) para as estacas ensaiadas à compressão e os valores da capacidade de carga das estacas próprias a esforços de tração, previstos por meio de métodos semi-empíricos próprios para esforços de compressão, considerando somente a parcela de resistência lateral e a inexistência da resistência de ponta. A capacidade de carga à tração das estacas injetadas autoperfurantes é equivalente a uma porcentagem de sua resistência lateral quando comprimida. Considerando-se ruptura estaca/solo, os valores previstos a favor da segurança são representados através dos métodos que anteriormente apresentaram menor resistência lateral.

TABELA 1: Resumo dos resultados das provas de carga.

\begin{tabular}{|c|c|c|c|c|c|c|c|c|}
\hline Local & $\begin{array}{l}\text { Ensaio } \\
\text { Estático }\end{array}$ & Tipo & $\begin{array}{c}\text { Estac } \\
\qquad a\end{array}$ & $\begin{array}{c}\text { Recalque } \\
\text { Total } \\
(\mathrm{mm})\end{array}$ & $\begin{array}{c}\text { Recalque } \\
\text { Residual } \\
\text { (mm) }\end{array}$ & $\begin{array}{c}\text { Carga de } \\
\text { Ruptura } \\
\text { Mazurkiewic } \\
\text { z (tf) }\end{array}$ & $\begin{array}{c}\text { Carga } \\
\text { de } \\
\text { Trabalho } \\
\text { (tf) }\end{array}$ & $\begin{array}{c}\text { Fator } \\
\text { de } \\
\text { Segurança }\end{array}$ \\
\hline \multirow{3}{*}{$\begin{array}{c}\text { (Base } \\
\text { NCQ-28) }\end{array}$} & \multirow{3}{*}{ Lento } & Compressão & EC-01 & 9,03 & 1,8 & 320 & 130 & 2,46 \\
\hline & & \multirow{2}{*}{ Tração } & ET-01 & 12,81 & 2,96 & 280 & 75 & 3,73 \\
\hline & & & ET-02 & 7,88 & 2,21 & 230 & 75 & 3,07 \\
\hline \multirow{3}{*}{$\begin{array}{c}\text { (Base } \\
\text { NCQ-23) }\end{array}$} & \multirow{3}{*}{$\begin{array}{c}\text { Rápida } \\
\text { até a } \\
\text { ruptur } \\
\text { a }\end{array}$} & Compressão & EC-01 & 16,05 & 3,51 & 290 & 120 & 2,42 \\
\hline & & & ET-01 & 12,7 & 1,48 & 160 & 60 & 2,67 \\
\hline & & Tração & ET-02 & 13,2 & 1,59 & 160 & 60 & 2,67 \\
\hline \multirow{3}{*}{$\begin{array}{c}\text { (Base } \\
\text { NCQ-11) }\end{array}$} & \multirow{3}{*}{ Lento } & Compressão & EC-01 & 6,1 & 1,17 & 210 & 75 & 2,80 \\
\hline & & \multirow{2}{*}{ Tração } & ET-01 & 4,5 & 0,39 & 92 & 37,5 & 2,45 \\
\hline & & & ET-02 & 4,76 & 0,43 & 90 & 37,5 & 2,40 \\
\hline
\end{tabular}


TABELA 2: Valores previstos pelos métodos para as obras ensaiadas a compressão.

\begin{tabular}{|c|c|c|c|c|c|c|c|c|c|c|c|}
\hline \multirow{5}{*}{ Estaca } & \multirow{5}{*}{ Método } & \multicolumn{5}{|c|}{ Ensaio a Compressão } & \multirow{5}{*}{$\begin{array}{c}\text { Carga } \\
\text { Média } \\
\text { Prevista } \\
\text { (tf) }\end{array}$} & \multirow{5}{*}{$\begin{array}{c}\text { Carga } \\
\text { de } \\
\text { Ruptura } \\
\text { (tf) }\end{array}$} & \multirow{5}{*}{$\%$} & \multirow{5}{*}{$\begin{array}{l}\text { Desvio } \\
\text { Padrão }\end{array}$} & \multirow{5}{*}{$\begin{array}{c}\text { Coeficiente } \\
\text { de Variação } \\
\text { (\%) }\end{array}$} \\
\hline & & \multirow{2}{*}{\multicolumn{5}{|c|}{$\begin{array}{c}\text { (RL: resistência lateral) } \\
\text { (RP: resistência de ponta) }\end{array}$}} & & & & & \\
\hline & & & & & & & & & & & \\
\hline & & \multicolumn{5}{|c|}{ (RT: resistência total) } & & & & & \\
\hline & & $\mathbf{R L}$ & $\%$ & RP & $\%$ & RT & & & & & \\
\hline \multirow{4}{*}{$\begin{array}{c}\text { (EC-01) } \\
\text { Base } \\
\text { NCQ-28 }\end{array}$} & $A \& V$ & 60 & 74 & 21 & 26 & 81 & \multirow{4}{*}{215} & \multirow{4}{*}{320} & 25 & \multirow{4}{*}{128} & \multirow{4}{*}{60} \\
\hline & $\mathrm{D} \& \mathrm{Q}$ & 155 & 93 & 12 & 7 & 167 & & & 52 & & \\
\hline & D.C & 349 & 91 & 35 & 9 & 384 & & & 120 & & \\
\hline & I.J.J & 113 & 50 & 113 & 50 & 226 & & & 71 & & \\
\hline \multirow{4}{*}{$\begin{array}{c}\text { (EC-01) } \\
\text { Base } \\
\text { NCQ-23 }\end{array}$} & $A \& V$ & 84 & 51 & 80 & 49 & 164 & \multirow{4}{*}{271} & \multirow{4}{*}{290} & 57 & \multirow{4}{*}{81} & \multirow{4}{*}{30} \\
\hline & $\mathrm{D \& Q}$ & 206 & 81 & 49 & 19 & 255 & & & 88 & & \\
\hline & D.C & 314 & 90 & 35 & 10 & 349 & & & 120 & & \\
\hline & I.J.J & 158 & 50 & 158 & 50 & 315 & & & 109 & & \\
\hline \multirow{4}{*}{$\begin{array}{c}\text { (EC-01) } \\
\text { Base } \\
\text { NCQ-11 }\end{array}$} & $A \& V$ & 47 & 40 & 71 & 60 & 118 & \multirow{4}{*}{165} & \multirow{4}{*}{210} & 56 & \multirow{4}{*}{31} & \multirow{4}{*}{19} \\
\hline & $D \& Q$ & 128 & 73 & 47 & 27 & 175 & & & 83 & & \\
\hline & D.C & 152 & 81 & 35 & 19 & 187 & & & 89 & & \\
\hline & I.J.J & 89 & 50 & 89 & 50 & 176 & & & 85 & & \\
\hline
\end{tabular}

\begin{tabular}{|c|c|c|c|c|c|c|c|c|}
\hline \multirow[t]{2}{*}{ Estaca } & \multirow[t]{2}{*}{ Método } & \multicolumn{2}{|c|}{$\begin{array}{c}\text { Ensaio a Compressão } \\
\text { (RL= } R T \text { resistência } \\
\text { lateral igual a } \\
\text { resistência total) }\end{array}$} & \multirow[t]{2}{*}{$\begin{array}{c}\text { Carga } \\
\text { Média } \\
\text { Prevista }\end{array}$} & \multirow[t]{2}{*}{$\begin{array}{c}\text { Carga } \\
\text { de } \\
\text { Ruptura } \\
\text { (tf) }\end{array}$} & \multirow[t]{2}{*}{$\%$} & \multirow[t]{2}{*}{$\begin{array}{l}\text { Desvio } \\
\text { Padrão }\end{array}$} & \multirow[t]{2}{*}{$\begin{array}{c}\text { Coeficiente } \\
\text { de } \\
\text { Variação } \\
\text { (\%) }\end{array}$} \\
\hline & & $R L=R T$ & $\%$ & & & & & \\
\hline (ET-01) & $A \& V$ & 60 & \multirow{4}{*}{100} & \multirow{4}{*}{169} & \multirow{4}{*}{255} & 24 & \multirow{4}{*}{126} & \multirow{4}{*}{74} \\
\hline (ET-02) & $D \& Q$ & 155 & & & & 61 & & \\
\hline Base & D.C & 349 & & & & 137 & & \\
\hline NCQ-28 & I.J.J & 113 & & & & 44 & & \\
\hline (ET-01) & $A \& V$ & 84 & \multirow{4}{*}{100} & \multirow{4}{*}{190} & & 53 & \multirow{4}{*}{96} & \multirow{4}{*}{51} \\
\hline (ET-02) & $D \& Q$ & 206 & & & & 129 & & \\
\hline Base & D.C & 314 & & & & 196 & & \\
\hline NCQ-23 & I.J.J & 158 & & & & 98 & & \\
\hline (ET-01) & $A \& V$ & 47 & \multirow{4}{*}{100} & \multirow{4}{*}{104} & \multirow{4}{*}{91} & 52 & \multirow{4}{*}{48} & \multirow{4}{*}{44} \\
\hline (ET-02) & $D \& Q$ & 128 & & & & 141 & & \\
\hline Base & D.C & 152 & & & & 167 & & \\
\hline NCQ-11 & I.J.J & 89 & & & & 98 & & \\
\hline
\end{tabular}




\subsection{CONSIDERAÇÕES SOBRE OS MÉTODOS APLICADOS}

A Figura 14-a e 14-b demonstram a adequabilidade e o desempenho dos métodos utilizados, sendo os métodos avaliados através da média dos valores da relação entre carga prevista e carga extrapolada, para as estacas ensaiadas a compressão e tração executadas em substratos arenosos.

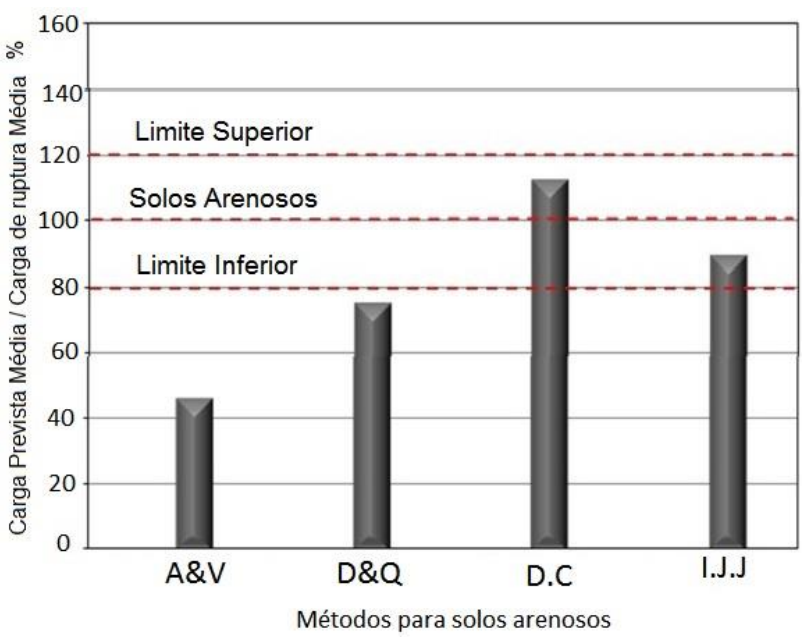

[a]

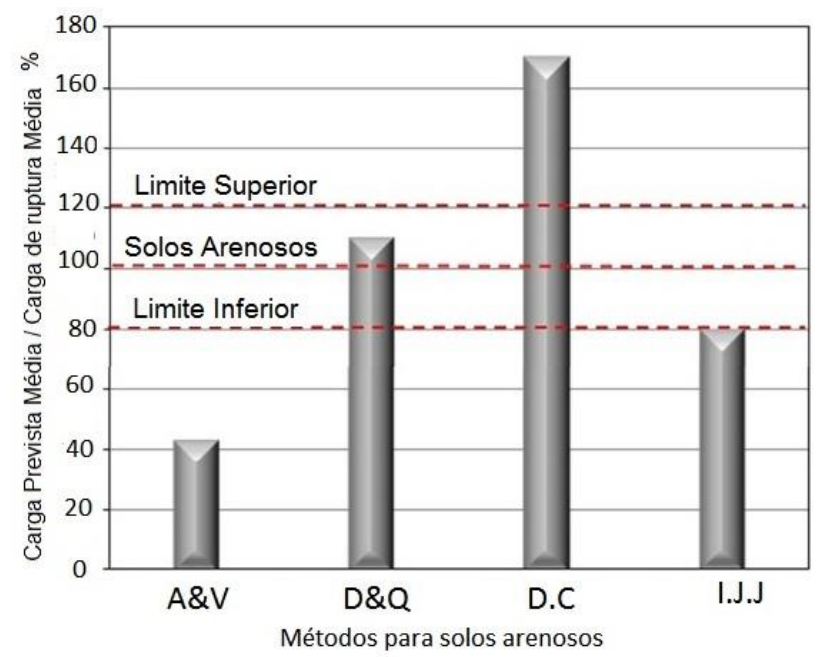

[b]

FIGURA 14: [a] Adequabilidade dos métodos em solo arenoso para estacas ensaiadas a compressão, [b] Adequabilidade dos métodos em solo arenoso para estacas ensaiadas a tração.

FONTE: Autoria Própria.

O Método de Decourt \& Quaresma (1978/1982), apresenta uma carga prevista bem mais conservadora, mas próximo da realidade para provas de cargas encerradas prematuramente. Com resistências laterais de 70 a 90 \% próximas da carga de ensaio, demonstrando-se coerente nos resultados com a geologia local, indicando que o atrito lateral seja considerado positivo no trecho do fuste ao longo da estaca, ao qual esta tende a recalcar mais do que o terreno circundante. 0 comportamento deste método está de acordo com a experiência relatada na literatura que enfatiza a pequena contribuição da resistência de ponta para este tipo de estaca. O método obteve boa aplicabilidade para previsão de carga em solos arenosos quando submetidos a cargas de tração. Tais valores de resistência lateral indicaram a aplicabilidade deste método na previsão da capacidade de carga à tração das estacas estudadas, os valores previstos resultaram na ordem de $70 \%$ dos valores medidos nas provas de carga, considerando a estaca como flutuante para avaliação do método.

Em relação ao Método de David Cabral (1986), desenvolvidos especialmente para estaca raiz, foi o que apresentou melhor desempenho entre todos os métodos baseado no $\mathrm{N}_{\mathrm{SPT}}$ mais próximo da realidade para as cargas de ensaio e ruptura submetidos à compressão axial. Sendo o método mais representativo para as estacas executadas em solos arenosos, os valores previstos resultaram na média da ordem de $80 \%$ dos valores medidos nas provas de carga, sendo sua resistência lateral mais elevada do que a carga de ponta, da ordem de até 7,0 vezes efetivamente comprovada. Pode-se considerar o grande mérito deste método pelo fato de levar-se em conta nas estimativas a pressão de ar comprimido aplicada durante a execução da estaca raiz. Pode-se inferir que é possível tal análise tomando como coeficiente de ajuste à pressão de injeção (p) especificada para estaca raiz injetada a baixa pressão, ajustando este coeficiente para uma pressão da ordem de 5 a 10 $\mathrm{kg} / \mathrm{cm}^{2}$ a mesma utilizada para injeção simultânea da estaca injetada autoperfurante.

\subsection{INTERPRETAÇÃO DOS DADOS EM RELAÇÃO AO ATRITO LATERAL E REAÇÃO DE PONTA}

As estacas injetadas autoperfurantes são estacas que distribuem sua resistência ao longo do fuste principalmente por atrito lateral, considerando-se favorável os valores preconizados 
pelos métodos de Decourt \& Quaresma e David Cabral. Os métodos apresentaram uma previsão de carga coerente com a realidade quando a estaca é submetida a esforços até a ruptura, mobilizando ao máximo o seu atrito lateral, contribuindo para as variações de transferência de carga apresentando uma boa definição para resistência lateral em relação a resistência de ponta.

Esta variação de resistência do solo ao longo do fuste contribuiu para o aumento do atrito lateral gerado na interação estaca/solo, demonstrado por estes métodos que utilizaram a resistência lateral como maior parcela da resistência total conseguindo atingir o valor próximo da carga de ruptura. Em termos de distribuição do atrito ao longo do fuste, as resistências laterais foram aumentando com a profundidade devido encontrar um substrato mais resistente.

Este comportamento pode ser observado para as estacas executadas ao longo do substrato geológico formado por areia (fina a compacta) apoiado em camada compacta. A resistência lateral média prevista por Decourt \& Quaresma para as estacas executadas em camadas de areia (fofa a compacta) foi de $82 \%$. Apresentando pouca disparidade para o método de David Cabral com $87 \%$, demonstrando que a estaca injetada autoperfurante para estes dois métodos exerce comportamento de uma estaca flutuante.

\section{CONSIDERAÇÕES FINAIS}

Os diversos fatores que influenciam na transferência de carga deste tipo de estaca estão relacionados à influência da pressão e o método de instalação da estaca, que se constitui na principal diferença entre as estacas injetadas convencionais. A utilização da aplicação de injeções constantes com pressões médias (5 á $10 \mathrm{~kg} / \mathrm{cm}^{2}$ ) nas estacas injetadas autoperfurantes, com pouca possibilidade de refluxo é um fator de destaque no aumento de sua capacidade de carga.

\section{Conforme} autoperfurantes deverá ocorrer aumento do atrito lateral através da compactação do terreno, devido ao aumento do diâmetro da perfuração ocasionado pela pressão da calda de cimento. Aumentando consequentemente a capacidade de carga da estaca, desta maneira seu fuste apresentará protuberâncias e irregularidades que aumentam sua rugosidade contribuindo com o atrito lateral. A transferência de carga das estacas injetadas autoperfurantes para o solo através do atrito lateral estaca-solo do corpo de calda de cimento, garante uma interação radial da barra de ancoragem no solo.

Em relação a carga de ruptura, o desempenho da previsão de carga, para Decourt \& Quaresma, foi satisfatório para verificação da capacidade de carga a tração em solos arenosos, reforçando a hipótese de ser um método específico para estacas que realizam a transferência de carga por atrito lateral, comprovando que sendo seus coeficientes em função do tipo da estaca ( $\alpha$ e $\beta$ ) podem se estender para este tipo de estaca.

Dos métodos de previsão de carga semiempíricos estudados, o que se destacou perante os demais quando em comparação com as provas de carga a compressão para arenosos (fofa a compacta) foi David Cabral. Desconsiderando em seus cálculos a pressão de golpes de ar para a estaca raiz, por pressões constantes utilizadas nas estacas injetadas autoperfurantes, foi verificada a coerência dos resultados em termos de resistência lateral, com o desempenho da estaca em estudo que trabalha fundamentalmente por atrito. Este sistema é similar a transferência de carga da microestaca tubular, pois ambas as estacas em conglomerado com o solo criam uma resistência à ruptura na seção do fuste.

\section{REFERÊNCIAS BIBLIOGRÁFICAS}

AUBRAM, D.; RACKWITZ, F.; SAVIDIS, S. A. Vibro-Injection Pile Installation in Sand: 1. Interpretation as MultiMaterial Flow. In: Proc Workshops DFG Research Unit FOR. 2015

ASCHENBROICH, H. Micro Pile Reinforcement Systems and Corrosion Protection. In: Micro-pile Seminar, 2001, Charlote . Anais... North Carolina : ADSC, 2001. v.1, p.112.

ASSOCIAÇÃO BRASILEIRA DE NORMAS TÉCNICAS (ABNT). Estacas: prova de carga estática. NBR 12131. Rio de Janeiro, 2006. 
ASSOCIAÇÃO BRASILEIRA DE NORMAS TÉCNICAS (ABNT). Projeto e execução de fundações. NBR 6122. Rio de Janeiro, 2010.

CAMBEFORT, H. Geotechnique de L' Ingenieur. Et reconnaissance de sols. Paris Editions Eyrolles, 1975. $424 p$.

CARBONARI, S., MORICI, M., DEZI, F., GARA, F., LEONI, G. Soil-structure interaction effects in single bridge piers founded on inclined pile groups. Soil Dynamics and Earthquake Engineering, v. 92, p. 52-67, 2017.

COSTA NUNES, A.J. Estacas injetadas - Relato geral. In: Seminário de Engenharia e Fundações Especiais, SEFE-1., 1985, São Paulo. Anais. São Paulo, ABMS, 1985. v.1, p.103- 118.

GRABE, J.; PUCKER, T. Improvement of bearing capacity of vibratory driven open-ended tubular piles. Frontiers in Offshore Geotechnics III -2015.

LAMARE NETO, A de; BERNARDES, G. P., COSTA F., L. M. J. Resultados de provas de carga executadas em pequeno diâmetro. In: Seminário de Engenharia e Fundações Especiais, SEFE-1., 1985, São Paulo. Anais. São Paulo, ABMS, 1985. v.1, p.163-173.

MARINO, M. T. R. D., FREIRE, G. S. S., HORN FILHO, N. O. $H$. F. Aspectos geológicos e geomorfológicos da zona costeira entre as praias do Futuro e Porto das Dunas, região metropolitana de Fortaleza,(RMF), Ceará, Brasil. Revista de Geologia, v. 25, n. 1, 2012.

MORAES. L.S. Estacas escavadas com base injetada. São Carlos, 2010. 154 p. Doutorado - Escola de Engenharia de São Carlos, Universidade de São Paulo.

PACHLA, $\mathrm{H}$. Conditions of proper interaction of lowpressure injection piles (LIP) with structure and soil, carrying capacity of pile anchorage in foundation. Studia Geotechnica et Mechanica, v. 38, n. 4, p. 33-49, 2016.

PESSANHA, J. F. M., BARCELOS, G. F. B., FARIA, A. V. C., FERREIRA, V. M. F. Análise estatística de registros anemométricos e seleção de turbinas eólicas: um estudo de caso. Centro, v. 3, p. 1, 2009.

SAMOKHVAL, M., ZAZULYA, J., MELNIKOV, R., MIRONOV, V. Design Calculation of Drill-Injection Piles with Controlled Broadening and Silty-Clayed Soil Foundation Basic Interaction Parameters. In: MATEC Web of Conferences. EDP Sciences, 2016. p. 01009.

SILVA, R. R. C. da. Estacas injetadas autoperfurantes: metodologia de execução e determinação da sua capacidade de carga através de métodos semiempíricos. 216p. Dissertação (Mestrado). Instituto de Pesquisas Tecnológicas - IPT, São Paulo. 2011.
SILVA, R. R. C. da. Confronto de estacas injetadas: Análise do comportamento a tração em solo residual da região mineira. In: SEFE Seminário de Engenharia e Fundações Especiais, 2015, São Paulo - SP. SEFE 8, 2015. v. 8. 